\title{
Parametric Analysis of the Defected Ground Structure-Based Hairpin Band Pass Filter for VSAT System on Chip Applications
}

\author{
Navya Ambati \\ Department of ECE \\ Koneru Lakshmaiah Education Foundation \\ Vaddeswaram, Guntur, Andhra Pradesh, India \\ M. Venkata Narayana \\ Department of ECE \\ Koneru Lakshmaiah Education Foundation \\ Vaddeswaram, Guntur, Andhra Pradesh, India \\ M. Sri Prapurna \\ Department of ECE \\ Koneru Lakshmaiah Education Foundation \\ Vaddeswaram, Guntur, Andhra Pradesh, India
}

\author{
Govardhani Immadi \\ Department of ECE \\ Koneru Lakshmaiah Education Foundation \\ Vaddeswaram, Guntur, Andhra Pradesh, India
}

\author{
Kalyan Reddy Bareddy \\ Department of ECE
}

Koneru Lakshmaiah Education Foundation

Vaddeswaram, Guntur, Andhra Pradesh, India

\section{Jayadeep Yanapu \\ Department of ECE}

Koneru Lakshmaiah Education Foundation

Vaddeswaram, Guntur, Andhra Pradesh, India

\begin{abstract}
In this study, a three-pole hairpin structure was fabricated on the top of the substrate material and an open loop microstrip structure at the ground to give a modified triple-band BPF with a unique design. A Rogers (RT5880) material with $\varepsilon_{\mathrm{r}}=$ 2.2 and thickness of $1.27 \mathrm{~mm}$ was used to fabricate the proposed structure. The space between two consecutive hairpin resonators has different distances $\mathrm{d} 1$ and $\mathrm{d} 2$ with values of $0.2 \mathrm{~mm}$ and $0.4 \mathrm{~mm}$ respectively. The proposed filter offers a compact size with low return loss. The equivalent LC circuit of the DGS and hairpin structure is obtained with the Ansys electronic desktop and by using simple circuit analysis. The desired microstrip triple-band BPF operates at the $\mathrm{Ku}$ band, resonates at $10.28 \mathrm{GHz}$, $12 \mathrm{GHz}$, and $14.62 \mathrm{GHz}$, while the simulated and experimental results are almost identical. The proposed wideband BPF satisfies the International Telecommunication Union ((ITU) region 3 spectrum requirements. Direct Broadcast Service (DBS) and Fixed Satellite Service (FSS) in transmit mode respectively employ the frequency band 11.41-12.92GHz and 14-14.5GHz.
\end{abstract}

Keywords-hairpin line BPF; DGS; microstrip transmission line; group delay; return loss; insertion loss

\section{INTRODUCTION}

International Telecommunication Union (ITU) has divided the world into three zones for satellite applications in order to efficiently organize the spectrum. The frequency bands for FSS in receive and transmit mode in region- 3 are $12.2-12.7 \mathrm{GHz}$ and $14-14.5 \mathrm{GHz}$ respectively. The reception and transmit frequencies for DBS are 11.7-12.2GHz and 17.3-17.8GHz. In modern wireless communication systems, $\mathrm{RF} /$ microwave filter is one of its indispensable components. The development of Corresponding author: Navya Ambati (ambatinavya88@gmail.com) transmission standards brought a fast-increasing growth of front-end RF devices and circuits [1, 2]. Their multi-band operation ability, system requirements, small sized filter, low cost, simple fabrication, and higher performance have attracted abundant interest. To satisfy these demands, attention has been centered on the microstrip printed filters because of their advantages in cost, size, and weight. DGS with periodic or aperiodic arrays allows a rejection range in some frequency bands to increase the effective inductance of a microstrip transmission line. These rejection properties of the DGS are available to many circuits such as coplanar antennas, power dividers, filter, etc. [5-7]. Bandpass Filters (BPFs) play a very important role in wireless communication applications due to their superior performance, minute size, and low attenuation within the prescribed pass band and high attenuation within the stop band. $\mathrm{Ku}$-band is a part of the electromagnetic spectrum in the microwave frequency range. It ranges from 12 to $18 \mathrm{GHz}$. The Ku-band is mostly used for TV and VSAT frameworks on boats. The band is split by the ITU into segments, modified by nations.

In this article, a new DGS is developed for the implementation of coupled line filter. An etched structure disrupts the shield current distribution in the ground plane. The properties of the transmission line, such as capacitance and inductance, can be affected by this disruption. As a result, the DGS is represented as an LC tank circuit $\lceil 3,4\rceil$. The circuit's Sparameters are calculated with a $3 \mathrm{D}$ finite element method simulator. 


\section{FILTER GEOMETRY}

The proposed filter's design was simulated in the Electromagnetic Field Simulator and is fabricated on a Rogers (RT5880) substrate with permittivity $\varepsilon_{r}=2.2$, loss tangent 0.0009 , and thickness of $1.27 \mathrm{~mm}$. The suggested microstrip hairpin line BPF has a size limit of $14 \times 16 \mathrm{~mm}^{2}$. The distances $d 1$ and $d 2$ for two consecutive hairpin resonators are distinct, with values $0.2 \mathrm{~mm}$ and $0.4 \mathrm{~mm}$ respectively. The ground-based microstrip open loop resonators act as a band rejection resonator. Here, we used 5 hairpin resonators to get an accurate range of frequency. The middle frequency corresponding to wavelength $(\lambda)$ is affected by the length of the hairpin structure. We can observe that there is a change in $f_{0}$ while increasing the length of the microstrip resonators $(L)$. A hairpin filter is designed at the $\mathrm{Ku}$ band by keeping the length resonators fixed. To obtain wide band width, the hairpin line BPF is manufactured with 5 resonators in the top plane, a dual armed microstrip resonator in the ground plane, while the ends of these resonators are connected to a $50 \Omega$ microstrip feed line.

(a)

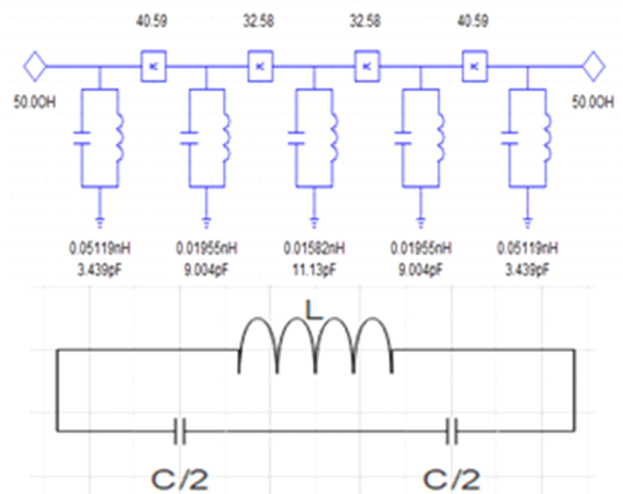

Fig. 1. Equivalent circuit diagram of the filter. (a) Hairpin BPF, (b) DGS.

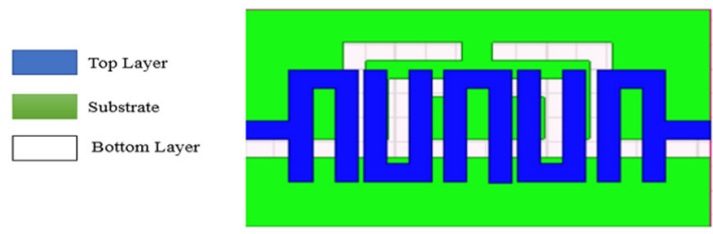

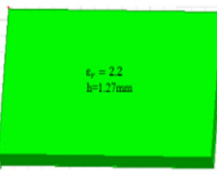

Substrate

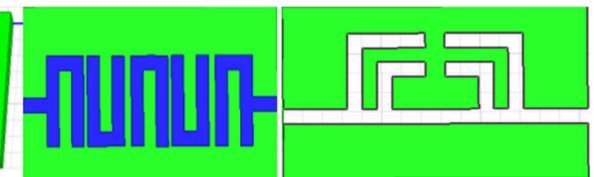

Fig. 2. Geometry of the proposed filter.

\section{A. Constructional Details of the Filter}

A hairpin line BPF with microstrip open loop resonators in the bottom of the substrate with dimensions is shown in Figure 2. Figure 3 shows the iteration-wise constructive design of a hairpin BPF with a defected ground structure.

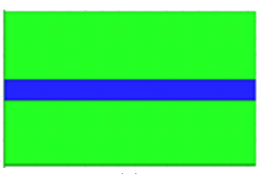

(a)

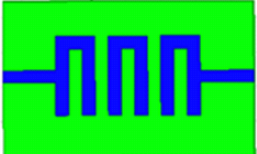

(d)

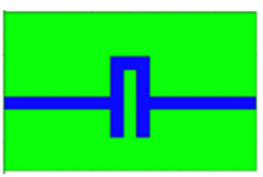

(b)

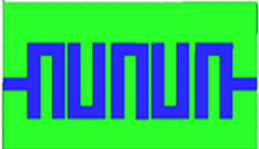

(e)

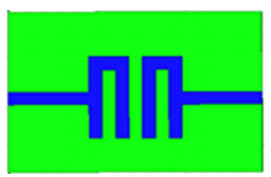

(c)

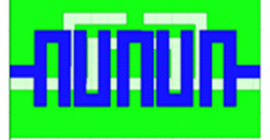

(f)
Fig. 3. Hairpin BPF with defected ground structure. (a) Basic shape, (b) iteration 1, (c) iteration 2, (d) iteration 3, (e) iteration 4, (f) iteration 5.

Iteration 0 is the basic microstrip transmission line with a length and width of $15.45 \mathrm{~mm}$ and $0.75 \mathrm{~mm}$. It is designed by using Ansoft HFSS. The length and width of the hairpin resonator are defined as $L$ and $W$ and are denoted by:

$$
L=\frac{\lambda g}{4}
$$

where the guided wavelength is given as

$$
\begin{gathered}
\lambda_{g}=\frac{\lambda_{0}}{4 F_{r} \sqrt{\varepsilon_{r_{e f f}}}}(2) \\
\varepsilon_{r e f f}=\frac{\varepsilon_{r}+1}{2}+\frac{\varepsilon_{r}-1}{2}\left[1+\left[\frac{12 h}{w}\right]\right]^{-1 / 2}
\end{gathered}
$$

where $h, \varepsilon_{r}$ are the thickness and relative permittivity of the substrate:

$$
\frac{w}{h}=\frac{2}{\Pi}\left\{(\mathrm{B}-1)-\ln (2 \mathrm{~B}-1) \frac{\varepsilon_{r}-1}{2 \varepsilon_{r}}\left[\ln (\mathrm{B}-1)+0.39-\left(\frac{0.61}{2 \varepsilon_{r}}\right)\right]\right\}
$$

where:

$$
B=\frac{60 \Pi^{2}}{z_{C \sqrt{\varepsilon_{r}}}}
$$

In iteration 1, a single hairpin structure is designed on the top of the substrate and is fed by a microstrip transmission line. In iteration 2, two hairpin structures are placed on the top of the substrate. In a similar manner, the hairpin structures are added one by one up to iteration 4 , and in the final step a defected ground structure is added to the existing hairpin structure to design a tri band BPF. The proposed design is designed to operate at $12 \mathrm{GHz}$. The three transmission zeros at the pass band frequency spectrum are obtained by the hairpin resonators and dual armed microstip open loop transmission resonators present in the filter.

\section{B. Evolution}

The step by step procedure of the proposed hairpin line BPF is represented in Figure 3. A $50 \Omega$ microstrip transmission line with a certain length and width will transfer the entire frequencies from one port to another. The hairpin resonators in the structure will reject the respective frequencies from hitting the load. In the second example, the energy flow from the source to the load can be altered by a single resonator. The power is coupled via the resonators from the source to the load, which results in a narrow pass band. It is simple to understand this with the help of Figure 4. 


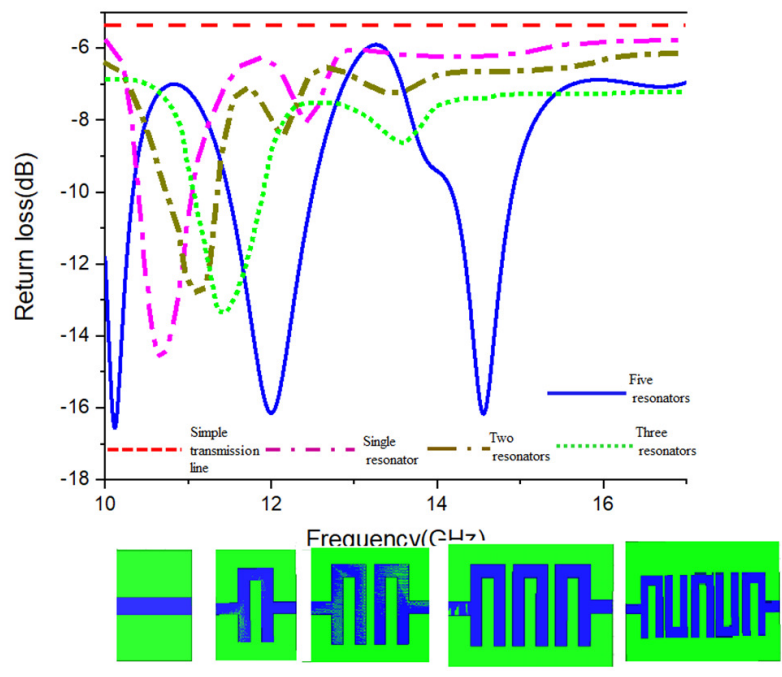

Fig. 4. Parametric analysis of the return loss of the proposed filter by successively adding the hairpin resonators.

\section{Filter Analysis}

Modeling and analysis of Hairpin line BPF with DGS was performed using HFSS. Their equivalent circuits were drawn with the Ansys electronic desktop. Examination of each filter parameter provided an insight into optimizing the design. The ground plane's microstrip transmission lines contain two transmission zeros at the two ends of the pass band frequency spectrum. In Tables I and II, the measurements used to design the microstrip open loop resonator and hairpin filter are shown.

TABLE I. RESONATOR MEASUREMENTS IN THE HAIRPIN LINE MICROSTRIP BPF

\begin{tabular}{|c|c|}
\hline Parameters & Values \\
\hline Substrate length (L) & $9 \mathrm{~mm}$ \\
\hline Substrate width (W) & $15.45 \mathrm{~mm}$ \\
\hline Resonator length (L0-L4) & $4.6 \mathrm{~mm}$ \\
\hline Resonator height (H0, H2) & $2.12 \mathrm{~mm}$ \\
\hline Resonator height (H1, H3) & $1.73 \mathrm{~mm}$ \\
\hline Resonator feed line length (F-F 10) & $0.75 \mathrm{~mm}$ \\
\hline Resonator feed line width (W1-W4) & $2.25 \mathrm{~mm}$ \\
\hline Resonator width (W, W0) & $1.5 \mathrm{~mm}$ \\
\hline
\end{tabular}

TABLE I. MEASUREMENTS OF THE MICROSTRIP OPEN LOOP RESONATORS IN THE BOTTOM PLANE

\begin{tabular}{|c|c|}
\hline Parameters & Values \\
\hline Resonator length (L0, L7) & $0.75 \mathrm{~mm}$ \\
\hline Resonator length (L1) & $5.37 \mathrm{~mm}$ \\
\hline Resonator length (L2) & $2.88 \mathrm{~mm}$ \\
\hline Resonator length (L3, L6) & $3.2 \mathrm{~mm}$ \\
\hline Resonator length (L4, L5) & $1.7 \mathrm{~mm}$ \\
\hline Resonator width (W0) & $8.903 \mathrm{~mm}$ \\
\hline Resonator width (W1, W2) & $3.95 \mathrm{~mm}$ \\
\hline Resonator width (W3, W4) & $3.2 \mathrm{~mm}$ \\
\hline Resonator width (W5, W6) & $1.7 \mathrm{~mm}$ \\
\hline Resonator width (W7, W8) & $3.275 \mathrm{~mm}$ \\
\hline Resonator width (W9) & $4.403 \mathrm{~mm}$ \\
\hline Resonator width (W10, W11) & $0.75 \mathrm{~mm}$ \\
\hline Resonator width (W12) & $1.003 \mathrm{~mm}$ \\
\hline
\end{tabular}

(a)

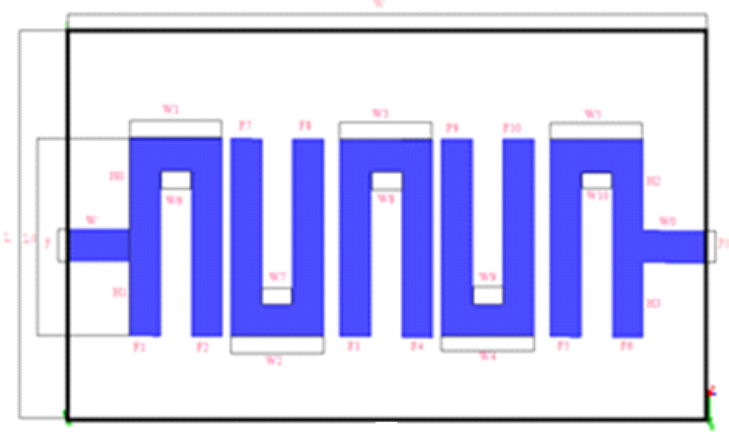

(b)

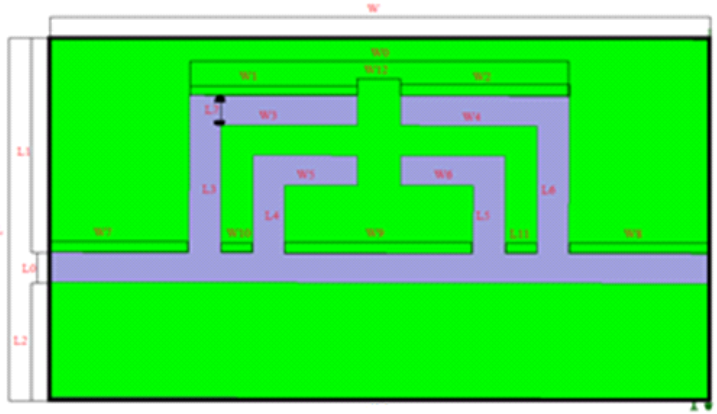

(c)

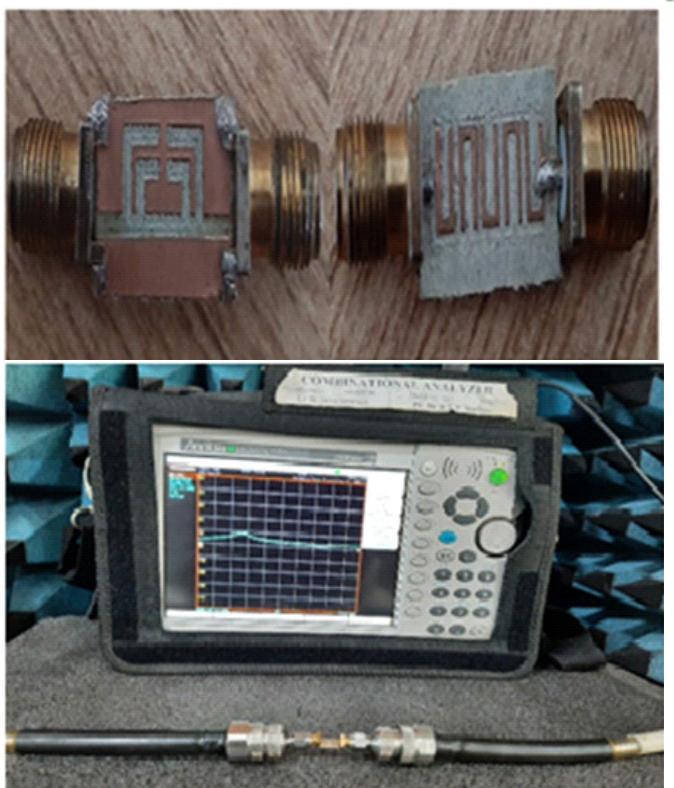

Fig. 5. (a) Top view and (b) bottom view of the proposed BPF. (c) The fabricated BPF. (d) Measuring the proposed BPF with a combinational analyzer.

The design goals of the proposed filter are the acquisition of a well specified reflection coefficient with wide bandwidth and of a transmission coefficient that allows satellite communication applications. The top and bottom views of the proposed microstrip hairpin line BPF are shown in Figure 5 and the dimensions used to design this filter are listed in Tables I and II.

\section{RESULTS AND DISCUSSION}

For real time validation, the built prototype was fabricated and tested. The plots show that the simulated and measured 
results are very close. The filter's return loss and insertion loss characteristics are detailed in Figure 7 and the reflection coefficient is below $10 \mathrm{~dB}$. The maximum possible filter's bandwidth is found to be $0.6 \mathrm{GHz}, 1.6 \mathrm{GHz}$, and $0.7 \mathrm{GHz}$. The insertion loss is far below $3 \mathrm{~dB}$ in all states and the insertion loss obtained is $0.8 \mathrm{~dB}$. Table III provides a summary of the performance parameters based on the literature, from which it is noted that the proposed filter offers better return loss, transmission coefficient, and a wider bandwidth. Figure 5(d) represents the measurement of a transmission coefficient by using the Anritsu combinational analyzer. The parameters that are measured with this combinational analyzer are the Sparameter, group delay, and phase delay.

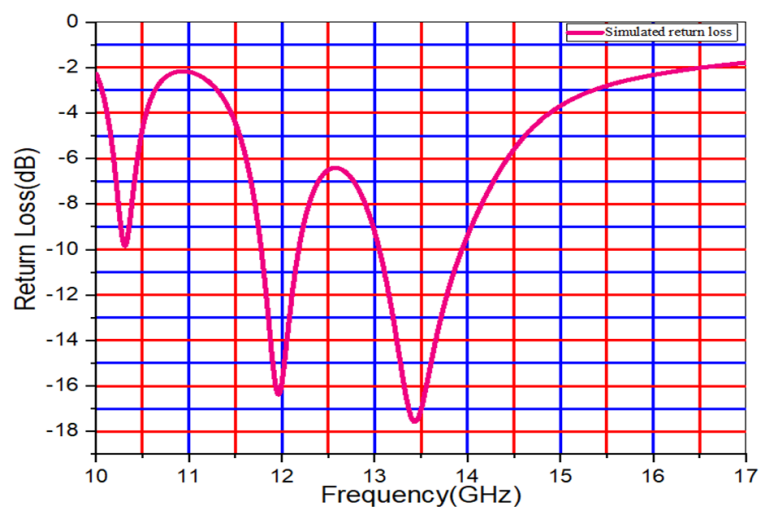

Fig. 6. Return loss of the hairpin BPF without DGS.

Figure 4 indicates the parametric analysis of the return loss obtained by successively adding the hairpin structures. The proposed filter is the iteration 5 which is of the basic shape, where the return loss and insertion loss characteristics are better than in other iterations. Figure 6 represents the return loss of the hairpin BPF without a DGS structure. Only two resonant bands are achieved at $12 \mathrm{GHz}$ and $13.5 \mathrm{GHz}$ with a return loss of $-16 \mathrm{~dB}$ and $-17.2 \mathrm{~dB}$.

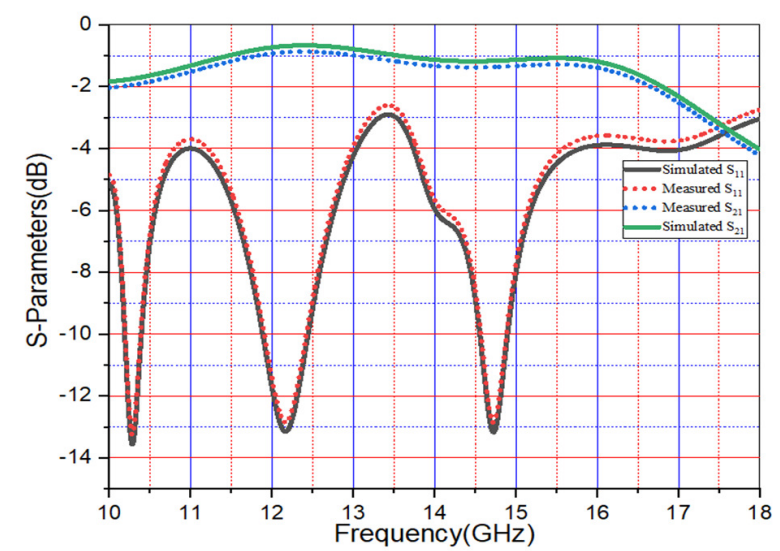

Fig. 7. Simulated vs measured results of return loss and insertion loss of the hairpin BPF with DGS.

Using the Vector Network Analyzer, the reflection coefficient of the manufactured filter was calculated. The proposed filter resonates at $10.28 \mathrm{GHz}, 12 \mathrm{GHz}$, and $14.62 \mathrm{GHz}$.
The relation between the measured and the computed group delay is shown in Figure 9. For the designed frequency band, the variance of reflection coefficient across frequencies is less than $10 \mathrm{~dB}$. The time domain characteristics of the microstrip hairpin line BPF are calculated by using group delay, as shown in Figure 9. With a deviation of $0.2 \mathrm{~ns}$, the group delay of the suggested filter is maximally flat. The delay induced by the filter is therefore consistent across the operating range, resulting in minimal signal distortion.

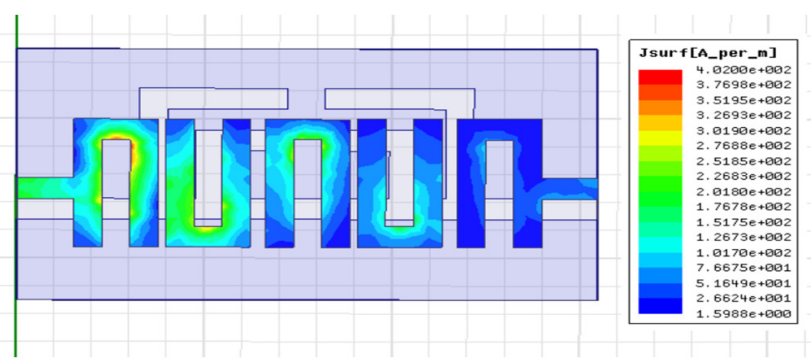

Fig. 8. Surface current distributions of the proposed BPF.

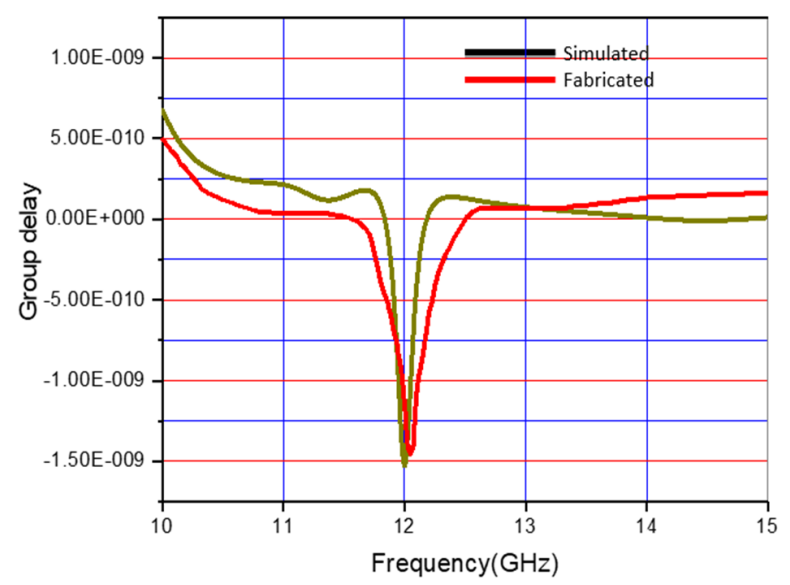

Fig. 9. Simulated vs measured results of group delay of the proposed filter.

The most important features for frequency and bandwidth of the proposed microstrip hairpin line BPF are:

- The proposed filter is designed to operate at the frequency of $12 \mathrm{GHz}$. We can easily control bandwidth and frequency.

- The method is much simpler than the complicated standard methods such as coupling reducers and switched delay lines.

- The filter's frequency and bandwidth tuning features are independent.

- This filter is fabricated on a less valuable dielectric material, making many operations inexpensive and simple to replicate. Without encroaching additional space, the two microstrip resonators are enclosed within the stepped loop structure.

- By varying the size of the hairpin resonators and microstrip open loop structure accordingly, this prototype can be modelled to work at any desired frequency. 
Table III compares the proposed wideband BPF with various known wide band BPFs at the $\mathrm{Ku}$ band. It is evident that the proposed wideband BPF has better bandwidth and insertion loss. Filters at the $\mathrm{Ku}$ band for satellite applications have been proposed in [8-11], but they all have narrower bandwidth and higher insertion loss. The proposed wideband $\mathrm{BPF}$ is compared with the bandpass filter proposed in [11] having high return loss, however the BPF has a bigger size and narrower bandwidth. Also, chemical etching microstrip devices without DGSs or vias also reduce process costs and improve manufacturing efficiency.

TABLE II. COMPARISON OF THE PROPOSED WITH KNOWN BPFS

\begin{tabular}{|c|c|c|c|c|c|}
\hline Ref. & Substrate & $\begin{array}{c}\text { Reflection } \\
\text { coefficient }\end{array}$ & $\begin{array}{c}\text { Group } \\
\text { delay }\end{array}$ & $\begin{array}{c}\text { Area } \\
\mathbf{( m m}^{\mathbf{2}}\end{array}$ & $\begin{array}{c}\text { Center } \\
\text { frequency }\end{array}$ \\
\hline$[8]$ & $\begin{array}{c}\text { Rogers } \\
\text { RT/duroid }\end{array}$ & $-14 \mathrm{~dB}$ & - & $5 \times 13$ & $13.3 \mathrm{GHz}$ \\
\hline$[9]$ & GaAs & $-15 \mathrm{~dB}$ & - & $1.09 \times 0.97$ & $13.5 \mathrm{GHz}$ \\
\hline$[10]$ & FR4 & $-16 \mathrm{~dB}$ & $0.5 \mathrm{~ns}$ & $11.12 \times 8$ & $14 \mathrm{GHz}$ \\
\hline$[11]$ & FR4 & $-11 \mathrm{~dB}$ & - & $25 \times 25$ & $10 \mathrm{GHZ}$ \\
\hline Proposed & $\begin{array}{c}\text { Rogers } \\
\text { RT5880 }\end{array}$ & $\begin{array}{c}-13.25 \mathrm{~dB} \\
-12.8 \mathrm{~dB} \\
-14.721 \mathrm{~dB}\end{array}$ & $0.2 \mathrm{~ns}$ & $14 \times 16$ & $\begin{array}{c}10.28 \mathrm{GHz} \\
12 \mathrm{GHz} \\
14.62 \mathrm{GHz}\end{array}$ \\
\hline
\end{tabular}

\section{CONCLUSION}

In this paper, a hairpin BPF with microstrip feed line having defected ground structure has been designed for $\mathrm{Ku}$ band satellite applications. The proposed three-pole hairpin $\mathrm{BPF}$ is designed for low transmission coefficient, steep pass band edges, high out band rejection, and wide bandwidth, with a frequency band covering the transmit mode of FSS and DBS services (ITU region-3) with an insertion loss of $0.2 \mathrm{~dB}$ and group delay of $0.2 \mathrm{~ns}$. In addition, the proposed filter is the first in this field to offer short group delay and large bandwidth, meeting the ITU Region 3 standards.

\section{REFERENCES}

[1] M. Richtarsic and J. Thornton, "Characterization and optimization of LTCC for high density large area MCM's," in Proceedings. 1998 International Conference on Multichip Modules and High Density Packaging (Cat. No.98EX154), Denver, CO, USA, Apr. 1998, pp. 9297, https://doi.org/10.1109/ICMCM.1998.670761.

[2] H. Miyake, S. Kitazawa, T. Ishizaki, T. Yamada, and Y. Nagatomi, "A miniaturized monolithic dual band filter using ceramic lamination technique for dual mode portable telephones," in 1997 IEEE MTT-S International Microwave Symposium Digest, Denver, CO, USA, Jun. 1997, vol. 2, pp. 789-792 vol.2, https://doi.org/10.1109/MWSYM.1997. 602908.

[3] J.-T. Kuo and H.-S. Cheng, "Design of quasi-elliptic function filters with a dual-passband response," IEEE Microwave and Wireless Components Letters, vol. 14, no. 10, pp. 472-474, Oct. 2004, https://doi.org/10.1109/ LMWC.2004.834560.

[4] M. Makimoto and S. Yamashita, "Bandpass Filters Using Parallel Coupled Stripline Stepped Impedance Resonators," IEEE Transactions on Microwave Theory and Techniques, vol. 28, no. 12, pp. 1413-1417, Dec. 1980, https://doi.org/10.1109/TMTT.1980.1130258.

[5] A. A. Sulaiman et al., "Design of hairpin band pass filters for K-Band application," in 2008 IEEE International RF and Microwave Conference, Kuala Lumpur, Malaysia, Dec. 2008, pp. 23-26, https://doi.org/10.1109/RFM.2008.4897401.

[6] Y. Di, P. Gardner, P. S. Hall, H. Ghafouri-Shiraz, and J. Zhou, "Multiple-coupled microstrip hairpin-resonator filter," IEEE Microwave and Wireless Components Letters, vol. 13, no. 12, pp. 532-534, Dec. 2003, https://doi.org/10.1109/LMWC.2003.819377.
[7] C.-K. Hsu, H.-H. Tung, and C.-H. Hsu, "Microstrip cross-coupled interdigital hairpin bandpass filter," in 2008 Asia-Pacific Microwave Conference, Dec. 2008, pp. 1-4, https://doi.org/10.1109/APMC.2008. 4958177.

[8] Q. Yang, X. Xiong, Y. Wu, L. Wang, and H. Xiao, "Design of microstrip tapped-hairpin dual-band pass filter for Ku-band application," in 2010 International Conference on Microwave and Millimeter Wave Technology, Chengdu, China, May 2010, pp. 772-774, https://doi.org/ 10.1109/ICMMT.2010.5525064.

[9] J. Sheen, Y.-H. Cheng, and W. Liu, "Ku-band Bandpass Filter Design with Compact Size and Broad Stopband by pHEMT Process," in 2019 PhotonIcs Electromagnetics Research Symposium - Spring (PIERSSpring), Rome, Italy, Jun. 2019, pp. 1022-1026, https://doi.org/10.1109/ PIERS-Spring46901.2019.9017867.

[10] C. S. Panda, R. Nayak, and S. K. Behera, "Design and analysis of a compact Substrate Integrated Waveguide bandpass filter for Ku band applications," in 2016 Online International Conference on Green Engineering and Technologies (IC-GET), Coimbatore, India, Nov. 2016, pp. 1-5, https://doi.org/10.1109/GET.2016.7916694.

[11] P. Sridharan and S. B.S, "Design and analysis of $1-10 \mathrm{GHz}$ band selected bandpass filter with broad tunable range," in 2014 International Conference on Communication and Signal Processing, Melmaruvathur, India, Apr. 2014, pp. 303-306, https://doi.org/10.1109/ICCSP.2014. 6949850.

[12] G. Zhiqiang, "A downsized and integrated C-band transceiver for VSAT," in Proceedings of 1995 SBMO/IEEE MTT-S International Microwave and Optoelectronics Conference, Rio de Janeiro, Brazil, Jul. 1995, vol. 1, pp. 33-36, https://doi.org/10.1109/SBMOMO.1995. 509594.

[13] J. S. Hong and M. J. Lancaster, Microstrip Filters for RF/Microwave Applications. New York, NY, USA: John Wiley \& Sons, 2001.

[14] M. Hayati, L. Noori, and A. Adinehvand, "Compact dual-band bandpass filter using open loop resonator for multimode WLANs," Electronics Letters, vol. 48, no. 10, pp. 573-574, May 2012.

[15] D. V. Doan, K. Nguyen, and Q. V. Thai, "A Novel Fuzzy Logic Based Load Frequency Control for Multi-Area Interconnected Power Systems," Engineering, Technology \& Applied Science Research, vol. 11, no. 4, pp. 7522-7529, Aug. 2021, https://doi.org/10.48084/etasr.4320.

[16] N. A. Zainurin, S. a. B. Anas, and R. S. S. Singh, "A Review of Battery Charging - Discharging Management Controller: A Proposed Conceptual Battery Storage Charging - Discharging Centralized Controller," Engineering, Technology \& Applied Science Research, vol. 11, no. 4, pp. 7515-7521, Aug. 2021, https://doi.org/10.48084/ etasr.4217.

[17] Z. A. Shamsan, "Statistical Analysis of 5G Channel Propagation using MIMO and Massive MIMO Technologies," Engineering, Technology \& Applied Science Research, vol. 11, no. 4, pp. 7417-7423, Aug. 2021, https://doi.org/10.48084/etasr.4264.

[18] G. Immadi, N. K. Majji, M. V. Narayana, and A. Navya, "Comparative Analysis of Pass Band Characteristics of a Rectangular Waveguide with and Without a Dielectric Slab," International Journal of Engineering and Advanced Technology, vol. 8, no. 6, pp. 1209-1211, Apr. 2019.

[19] G. Immadi, M. V. Narayana, A. Navya, Y. D. S. Sairam, and K. Shrimanth, "Design and Analysis of Micro strip Circular Ring Band Stop Filter," International Journal of Engineering and Advanced Technology, vol. 8, no. 4, pp. 788-790.

[20] G. Immadi, M. V. Narayana, A. Navya, M. S. V. S. L. Sreejasree, D. S. Krishna, and V. S. Sindhu, "Analysis of Z-Shaped Microstrip Bandpass Filter at Ku Band," International Journal of Advanced Science and Technology, vol. 29, no. 5, pp. 8341-8344, May 2020.

[21] G. Immadi, M. V. Narayana, A. Navya, M. S. V. S. L. Sreejasree, D. S. Krishna, and V. S. Sindhu, "Design of Circular Ring Resonator Microstrip Band Pass Filter at Ku Band," Journal of Critical Reviews, vol. 7, no. 13 , pp. 465-467, Jun. 2020, https://doi.org/10.31838/jcr.07. 13.81 .

[22] G. Imamdi, M. V. Narayan, A. Navya, and A. Roja, "Reflector array antenna design at millimetric ( $\mathrm{mm}$ ) band for on the move applications," ARPN Journal of Engineering and Applied Sciences, vol. 13, no. 1, pp. 352-359, 2018. 